\title{
Cell death in HeLa cells upon imperatorin and cisplatin treatment
}

\author{
Joanna Jakubowicz-Gil' ${ }^{1}$, Roman Paduch ${ }^{2}$, Zofia Ulz ${ }^{3}$, Dorota Badziul ${ }^{1}$, \\ Kazimierz Głowniak ${ }^{4}$, Antoni Gawron ${ }^{1}$ \\ ${ }^{1}$ Department of Comparative Anatomy and Anthropology, Maria Curie-Sklodowska University, \\ Lublin, Poland \\ ${ }^{2}$ Department of Virology and Immunology, Maria Curie-Sklodowska University, Lublin, Poland \\ ${ }^{3}$ Main Pharmaceutical Inspectorate, Warsaw, Poland \\ ${ }^{4}$ Department of Pharmacognosy with Medicinal Plant Laboratory, Skubiszewski Medical University, \\ Lublin, Poland
}

\begin{abstract}
There is growing evidence that commonly applied chemotherapy regimens can be improved by introducing new, specific, active and low side-effect drugs, or by combining substances to obtain the required clinical effect. The aim of the present study was to investigate the effects of imperatorin and cisplatin, applied separately or in combination, on apoptosis, necrosis and autophagy induction in the human cervical carcinoma cell line (HeLa). Imperatorin appeared to be a potent autophagy inducer, rather than a necrotic or apoptotic one. In contrast, cisplatin induced mainly apoptosis and necrosis after $6 \mathrm{~h}$ and $24 \mathrm{~h}$, while longer incubation resulted only in necrosis induction. When HeLa cells were incubated with both drugs, autophagy appeared most frequently, although to a smaller extent than that observed after imperatorin administered alone. At the molecular level, autophagy was correlated with the presence of the cleaved form of microtubule-associated protein 1 light chain LC3 - LC3II. It was also accompanied by the inhibition of heat shock proteins Hsp27 and Hsp72 expression. Our results indicate that imperatorin alone, or in combination with cisplatin, is mainly an autopahgy inducer in HeLa cells. (Folia Histochemica et Cytobiologica 2012, Vol. 50, No. 3, 381-391)
\end{abstract}

Key words: imperatorin, cisplatin, cell death, HeLa, Hsp

\section{Introduction}

Imperatorin (IMP, 8-isopentenyloxypsoralene) belongs to the furanocoumarin family. It is a natural compound occurring in lemon, lime oils and popular culinary herbs like parsnip, fennel and parsley [1]. Imperatorin shows potent pharmacological activity and has been studied for its anti-inflammatory and antitumor properties. It has shown an antiproliferative effect on several cancer cell lines [2]. Suppression of cell

Correspondence address: J. Jakubowicz-Gil,

Department of Comparative Anatomy and Anthropology,

Maria Curie-Sklodowska University

Akademicka Str. 19, 20-033 Lublin, Poland;

tel.: + 488153759 96, fax: + 488153751 01;

e-mail: jjgil@poczta.umcs.lublin.pl proliferation and induction of apoptosis have been suggested as possible mechanisms for its anticancer activity [3]. Imperatorin inhibits the expression of cyclin D1 and induces G0/G1 cell cycle arrest in HeLa cells followed by apoptosis [4]. It also affects reactive oxygen species (ROS) production, induces mitochondrial membrane depolarization, decreases the level of antiapoptotic Bcl-2 and Bcl-x, and increases the proapoptotic Bax expression. Imperatorin promotes release of cytochrome $\mathrm{c}$ and activation of caspase 3 before leading to apoptosis [5]. Significant pro-apoptotic potential of imperatorin has also been confirmed by in vivo studies with nude mice bearing human hepatoma HepG2 cells [37]. In contrast, some authors have observed a mutagenic effect of imperatorin and transformation of the mouse fibroblast cell line $[6,7]$. 
Cisplatin (CP, cis-dichlorodiammine-platinum (II)) is an important chemotherapeutic agent widely used in clinical treatment against several malignancies like ovarian, cervical, testicular, bladder, lung, gastric, head and neck cancers. At the molecular level, it interacts with cellular proteins and lipids and forms DNA adducts causing cell cycle arrest in G2/M phase [8-10]. It can also disturb cytoskeleton organization [11]. It may induce apoptosis through caspase 3-dependent and -independent signaling pathways. It has been shown that alteration in caspase 3 expression and activity were associated with the development of cellular resistance to cisplatin $[12,13]$. There are also several other factors responsible for such resistance. One of them is heat shock proteins (Hsps) overexpressed in nearly all classes of tumors [14-17]. These are molecular chaperones, controlling proper folding of newly synthesized polypeptides, refolding of misfolded proteins, and controlling translocation through cell membranes protecting against cell death [18-21]. Therefore, tumour cell resistance to apoptosis is thought to be closely associated with Hsps overexpression, which indicates poor prognosis. Up-regulation of small heat shock protein Hsp27 has been observed in multiple malignancies including squamous cell carcinoma, gastric carcinoma, ovarian carcinoma and acute myeloid leukemia. High expression of Hsp72 has been reported in high grade malignant tumors such as pancreatic cancer, colorectal carcinoma, breast cancer, endometrial cancer, osteosarcoma and renal cell tumors. Overexpression of both proteins has also been found in cisplatin resistant human ovarian and cervical tumor cells [38]. Therefore, it seems that decreasing the Hsps level in cancer cells would be beneficial to patients.

Another type of programmed cell death observed in cancer cells is autophagy. This is caspase-independent cell death characterized by the accumulation of autophagic vacuoles in the cytoplasm accompanied by degradation of the Golgi apparatus and ER, preceding destruction of the nucleus. Autophagy is suppressed during the early stages of tumor progression. Therapeutically increased autophagy could represent an alternative way to destroy the cancer [22].

It is known that natural bioactive compounds may act in synergy with chemotherapeutics used in clinical treatment in programmed cell death induction. They also diminish the side effects of cytostatic drugs. Thus, the aim of our study was to investigate the effects of imperatorin and cisplatin, applied alone or in combination, on apoptosis, necrosis and autophagy induction in HeLa cells.

\section{Material and methods}

Cells and culture conditions. Human cervix carcinoma cell line (HeLa B, ECACC No 85060701) cultured in RPMI 1640 medium supplemented with 5\% FBS (fetal bovine serum) $(\mathrm{v} / \mathrm{v})$ was used in this study. Cells were seeded on cover slides (for cell death detection) or in Falcon vessels (for heat shock proteins, caspase 3 and LC3 identification), at a density of $1 \times 10^{5} \mathrm{cells} / \mathrm{ml}$ and incubated at $37^{\circ} \mathrm{C}$ in humidified atmosphere with $5 \% \mathrm{CO}_{2}$.

Drug treatment. Imperatorin was isolated from the fruits of Angelica archangelica (Hofm) by column chromatography [39]. Imperatorin at final concentrations of $50 \mu \mathrm{M}$, $100 \mu \mathrm{M}, 150 \mu \mathrm{M}$, and $200 \mu \mathrm{M}$, and cisplatin (Sigma) at final concentrations of $2 \mu \mathrm{M}$, and $5 \mu \mathrm{M}$ were used in the experiments. The drugs were dissolved in dimethyl sulfoxide (DMSO, Sigma). The final concentration of DMSO in the culture medium did not exceed $0.01 \%$, which, as indicated in preliminary experiments, did not influence cell viability or the expression of the proteins studied.

Three variants of drug treatment were performed:

1. The first variant - HeLa cells were incubated only with imperatorin or cisplatin for 6 h, $24 \mathrm{~h}$ and $48 \mathrm{~h}$;

2. The second variant - imperatorin and cisplatin were added to the culture medium at the same time and incubated for $24 \mathrm{~h}$;

3. The third variant - the cells were preincubated with imperatorin for $6 \mathrm{~h}$ followed by cisplatin treatment for the next $18 \mathrm{~h}$; - the cells were preincubated with cisplatin for $6 \mathrm{~h}$ followed by imperatorin addition for the next $18 \mathrm{~h}$.

As a control, the cells were incubated with $0.01 \%$ of DMSO.

Immunoblotting. After imperatorin and/or cisplatin treatment, HeLa cells were lysed in a hot SDS-loading buffer (125 mM Tris- $\mathrm{HCl}$ pH 6.8; 4\% SDS; $10 \%$ glycerol; $100 \mathrm{mM}$ DTT), boiled in a water bath for $10 \mathrm{~min}$, centrifuged at 10,000 $\mathrm{g}$ for $10 \mathrm{~min}$, and the supernatants were collected. The protein concentration was determined using the Bradford method [23], and samples of the supernatants containing $80 \mu \mathrm{g}$ of proteins were separated by $10 \%$ SDS-polyacrylamide gel electrophoresis [24], and subsequently transferred onto Immobilon $\mathrm{P}$ membrane (Sigma). Following the transfer, the membrane was blocked with $3 \%$ low fat milk in PBS for $1 \mathrm{~h}$, and incubated overnight with mouse monoclonal antibody anti-Hsp72 (SPA 810, StressGen) diluted 1:1,000, anti-Hsp27 (SPA 800, StressGen) diluted 1:1,000, and rabbit antibodies anticaspase 3 active form (Sigma) diluted 1:500, anti-LC3 (Sigma) diluted 1:1,000. The membranes were washed 3 times for $10 \mathrm{~min}$ with PBS containing $0.05 \%$ Triton X-100 (Sigma) and incubated for $2 \mathrm{~h}$ with a 1:30,000 dilution of alkaline phosphatase-conjugated anti-mouse IgG 
or anti-rabbit IgG (Sigma). The membranes were visualized with an alkaline phosphatase substrate (5-bromo-4-chloro-3-indolylphosphate and nitro-blue tetrazolium, Sigma) in a color development buffer (DMF, Sigma). The data was normalized relative to $\beta$-actin (Sigma, working dilution 1:2,000).

The level of protein expression was determined using Bio-Profil Bio-1D Windows Application V.99.03 program. Three independent experiments were performed.

Apoptosis detection with fluorochromes. For apoptosis and necrosis identification, the cells were stained with fluorescent dye Hoechst 33342 (Sigma) and propidium iodide (Sigma), respectively [25]. Morphological analysis was performed under a fluorescence microscope (Nikon $\mathrm{E}-800)$. Cells exhibiting blue fluorescent nuclei (fragmented and/or with condensed chromatin) were interpreted as apoptotic. Cells exhibiting pink fluorescent nuclei were interpreted as necrotic. At least 1,000 cells in randomly selected microscopic fields were counted under the microscope. Each experiment was performed in triplicate.

Detection of acidic vesicular organelles with acridine orange. Autophagy is a process of sequestrating cytoplasmic proteins into the lytic compartment and is characterized by the formation and promotion of acidic vesicular organelles (AVOs). To detect AVOs in HeLa cells treated with imperatorin and/or cisplatin, vital staining with acridine orange was performed [26]. The cells were incubated with the fluorochrome at a final concentration of $1 \mu \mathrm{g} / \mathrm{ml}$ for $15 \mathrm{~min}$. Typical orange acridine - positive cells exhibited granular discretion of AVOs in the cytoplasm, indicative of autophagosome formation. Morphological analysis was performed under a fluorescence microscope (Nikon E - 800). At least 1,000 cells in randomly selected microscopic fields were counted under the microscope. Each experiment was performed in triplicate. The percentage of autophagic cells was calculated as the number of cells with AVOs versus the total number of stained cells.

Combination index. Determination of drug synergy or antagonism was quantified by the combination index (CI) [27]. CI provides a quantitative measure of the extent of drug interaction and the numerical value was calculated as described in this equation:

\section{$\mathrm{CI}=\frac{\text { Cisplatin } \%+\text { Imperatorin } \%}{\text { Cisplatin } / \text { Imperatorin } \%}$}

Cisplatin $\%$ and Imperatorin $\%$ mean the percentage of dead cells after treatment with separate drugs, and Cisplatin/Imperatorin $\%$ after treatment with both drugs. $\mathrm{CI}=1$ indicates an additive effect, $<1-$ synergy, while $>1$ - antagonism.
Statistical analysis. Data is presented as the mean of results \pm SD coming from three independent experiments. Statistical evaluation was performed with one-way Anova test followed by Dunnet's multiple comparison test. $\mathrm{p}<0.05$ compared to the control was taken to be the criterion of significance.

\section{Results}

\section{Effects of cisplatin and imperatorin on apoptosis, necrosis and autophagy}

For apoptosis, necrosis or autophagy estimation, control HeLa cells and cells treated with imperatorin and cisplatin separately, or in combination, were stained with Hoechst 33342, propidium iodide and acridine orange, respectively.

Imperatorin appeared to be an effective autophagy inducer rather than an apoptotic or necrotic one (Figure 1A). Our studies revealed a correlation between the drug concentration, incubation time and the number of autophagic cells. After $6 \mathrm{~h}$ of treatment, a not very high, but statistically significant, increase in the number of programmed dead cells was observed only after $100 \mu \mathrm{M}$ of imperatorin. The highest percentage (18\%) of autophagic cells was observed after $24 \mathrm{~h}$ of treatment with the $100 \mu \mathrm{M}$ concentration of the drug. Higher concentrations were less effective, and a gradual decrease in the number of autophagic cells was observed. After treatment with 200 $\mu \mathrm{M}$, only about $6 \%$ of autophagic cells were found. After $48 \mathrm{~h}$ of treatment, a higher level of autophagic cells was observed after application of $150 \mu \mathrm{M}$ of the drug (about 16\%) and a dramatically decreased level when $200 \mu \mathrm{M}$ was used.

In contrast to imperatorin, incubation of HeLa cells with cisplatin at the concentrations of $2 \mu \mathrm{M}$ and $5 \mu \mathrm{M}$ was less effective in autophagy induction (Figure 1B). The $24 \mathrm{~h}$ and $48 \mathrm{~h}$ incubations resulted in a significant increase in the number of apoptotic cells, especially after treatment with $5 \mu \mathrm{M}$ of the drug (about 8\%). After a longer incubation time, the apoptosis level was sustained, but it was accompanied by significant necrosis induction.

When HeLa cells were incubated with both drugs, autophagy was observed most frequently, but to a smaller extent than after treatment with imperatorin alone (Figure 2, Table 1). The intensity of the process depended on the drug concentrations and not significantly on the order of drug administration. Treatment with imperatorin at a concentration of $100 \mu \mathrm{M}$ and cisplatin $2 \mu \mathrm{M}$ was the most effective, and about $10-12 \%$ of autophagic cells were observed in each 
A

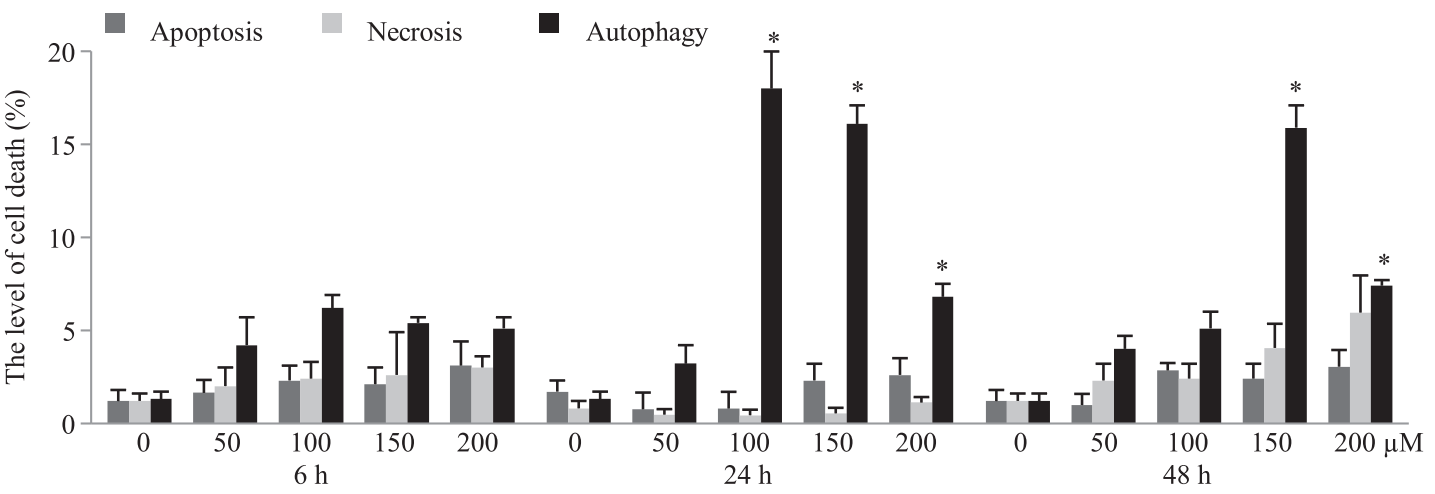

Imperatorin $(\mu \mathrm{M})$

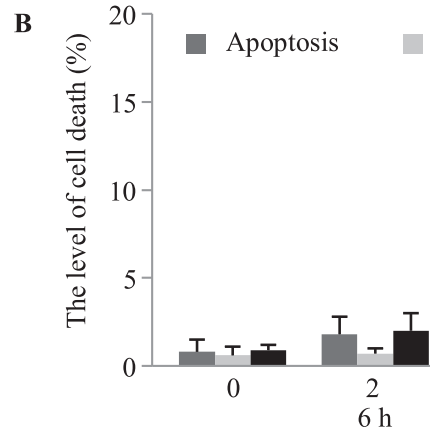

C

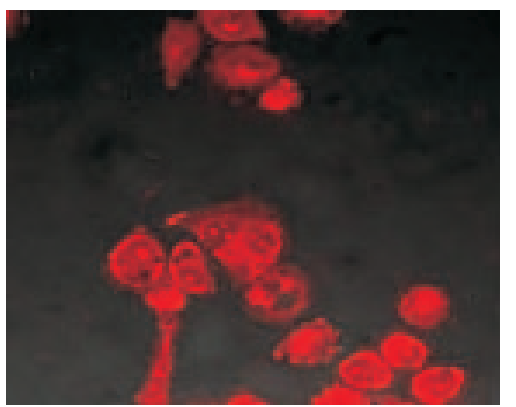

D

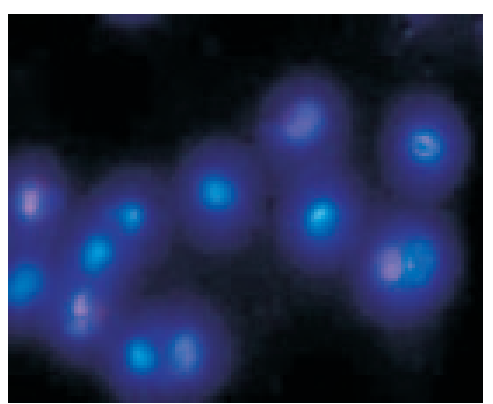

E

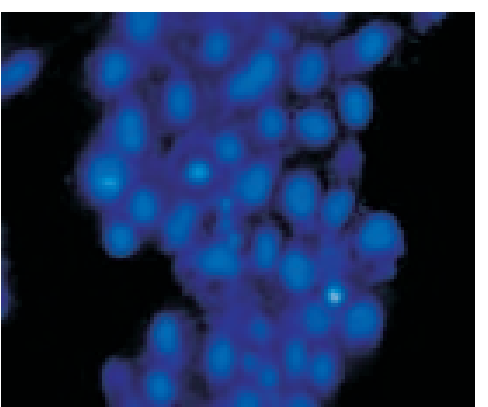

Figure 1. The effects of different imperatorin (A) concentrations $(0-200 \mu \mathrm{M})$ and cisplatin $(\mathbf{B})$ concentrations $(0-5 \mu \mathrm{M})$ on the levels of apoptosis, necrosis and autophagy induction in HeLa cells after $6 \mathrm{~h}, 24 \mathrm{~h}$ and $48 \mathrm{~h}$ of treatment. C - picture of autophagic cells stained with acridine orange after $24 \mathrm{~h}$ incubation with imperatorin $(100 \mu \mathrm{M})$, D - picture of apoptotic and necrotic cells stained with Hoechst 33342 and propidium iodide after 24 h simultaneous incubation with cisplatin $(5 \mu \mathrm{M})$ and imperatorin $(150 \mu \mathrm{M}), \mathbf{E}-$ picture of apoptotic and necrotic cells stained with Hoechst 33342 and propidium iodide after $24 \mathrm{~h}$ incubation with cisplatin $(5 \mu \mathrm{M})$. ${ }^{*} \mathrm{p}<0.05$

incubation variant (Figures $2 \mathrm{~A}-\mathrm{C}$ ). Co-incubation of HeLa cells with cisplatin $2 \mu \mathrm{M}$ and imperatorin $150 \mu \mathrm{M}$ at the same time was toxic to the cell culture and about $25 \%$ of necrotic cells were observed (Figure $2 \mathrm{~A}$ ). Incubation of $\mathrm{HeLa}$ cells with cisplatin $5 \mu \mathrm{M}$ and imperatorin at different concentrations was less effective in autophagy induction than cisplatin $2 \mu \mathrm{M}$ (Figures 2D-F). The highest percentage of autophagic cells was noted after treatment with $100 \mu \mathrm{M}$ of imperatorin, especially when HeLa cells were preincubated with cisplatin. Incubation with higher imperatorin concentrations result- ed in strong necrosis in all the drug combinations studied. Neither drug, in all the combinations studied, had a significant effect on apoptosis induction.

\section{Effects of imperatorin and cisplatin on Hsp72, Hsp 27, caspase 3 and LC 3 expression}

Apoptosis and autophagy at the molecular level are characterized by the expression of some marker proteins. Thus, we decided to estimate the level of caspase 3, LC3 as well as selected heat shock protein expression. 
Table 1. Combination index (CI) analysis of combined treatment of HeLa with imperatorin (IMP) and cisplatin (CP) for 24 hours. A - treatment with both drugs at the same time; B - cisplatin pretreatment followed by incubation with imperatorin; $\mathrm{C}$ - imperatorin pretreatment followed by cisplatin incubation; CI > 1 antagonism; CI < 1 synergism; $\mathrm{CI}=1$ additive effect

\begin{tabular}{|c|c|c|c|c|c|c|c|c|c|}
\hline \multirow[t]{2}{*}{$\mathbf{A}$} & \multicolumn{3}{|c|}{ IMP $50 \mu \mathrm{M}$} & \multicolumn{3}{|c|}{ IMP $100 \mu \mathrm{M}$} & \multicolumn{3}{|c|}{ IMP $150 \mu \mathrm{M}$} \\
\hline & Ap & Nk & Aut & Ap & Nk & Aut & Ap & Nk & Aut \\
\hline $\begin{array}{l}2 \mu \mathrm{M} \\
\mathrm{CP}\end{array}$ & 3.5 & 2.3 & 2.2 & 2.3 & 2.3 & 1.6 & 2.3 & 0.3 & 6 \\
\hline $\begin{array}{l}5 \mu \mathrm{M} \\
\mathrm{CP}\end{array}$ & 5.5 & 2.7 & 1.6 & 2.7 & 4 & 4 & 1.6 & 0.6 & 2.3 \\
\hline \multirow[t]{2}{*}{ B } & \multicolumn{3}{|c|}{ IMP $50 \mu \mathrm{M}$} & \multicolumn{3}{|c|}{ IMP $100 \mu \mathrm{M}$} & \multicolumn{3}{|c|}{ IMP $150 \mu \mathrm{M}$} \\
\hline & Ap & Nk & Aut & Ap & Nk & Aut & Ap & Nk & Aut \\
\hline $\begin{array}{l}2 \mu \mathrm{M} \\
\mathrm{CP}\end{array}$ & 2.3 & 2.3 & 1.3 & 3.5 & 3.5 & 1.7 & 2.3 & 2.3 & 6.3 \\
\hline $\begin{array}{l}5 \mu \mathrm{M} \\
\mathrm{CP}\end{array}$ & 2.8 & 2.8 & 1.6 & 5.5 & 2.7 & 1.5 & 3.7 & 0.3 & 2.6 \\
\hline \multirow[t]{2}{*}{ C } & \multicolumn{3}{|c|}{ IMP $50 \mu \mathrm{M}$} & \multicolumn{3}{|c|}{ IMP $100 \mu \mathrm{M}$} & \multicolumn{3}{|c|}{ IMP $150 \mu \mathrm{M}$} \\
\hline & Ap & Nk & Aut & Ap & Nk & Aut & Ap & Nk & Aut \\
\hline $\begin{array}{l}2 \mu \mathrm{M} \\
\mathrm{CP}\end{array}$ & 1.4 & 1.4 & 1.2 & 2.3 & 3.5 & 1.9 & 2.3 & 2.3 & 6.3 \\
\hline $\begin{array}{l}5 \mu \mathrm{M} \\
\mathrm{CP}\end{array}$ & 5.5 & 4 & 1.3 & 5.5 & 2 & 2 & 3.7 & 0.7 & 3.6 \\
\hline
\end{tabular}

\section{Heat shock proteins}

The effects of imperatorin and cisplatin on the expression of Hsp27 and Hsp72 were drug- and concentration-dependent (Figures 3, 4). As shown in Figure 3, both drugs added to the culture medium, separately or in combination, generally were good inhibitors of Hsp27. Imperatorin was most potent after $24 \mathrm{~h}$ of treatment at the concentration of $100 \mu \mathrm{M}$ (about $50 \%$ ). Cisplatin diminished the protein level less effectively and the greatest inhibition was observed after $24 \mathrm{~h}$ and $48 \mathrm{~h}$ of incubation (about $80 \%$ ). In the case of the drug combinations, simultaneous treatment of HeLa cells with imperatorin $150 \mu \mathrm{M}$ and cisplatin $5 \mu \mathrm{M}$ resulted in strong (about 20\%) inhibition of Hsp27. Overexpression was observed only in one case - when HeLa cells were incubated with imperatorin at the concentration of $50 \mu \mathrm{M}$ for $24 \mathrm{~h}$ $(160 \%)$. In the case of Hsp72, imperatorin inhibited the protein level only after $48 \mathrm{~h}$ of incubation with $150 \mu \mathrm{M}$ and $200 \mu \mathrm{M}$ (about 25\%), while cisplatin had no significant effect on the protein expression. A combination of both drugs, significantly or not, generally inhibited Hsp72 expression in all the variants studied. Overexpression was observed after $24 \mathrm{~h}$ of incubation with $50 \mu \mathrm{M}$ and $200 \mu \mathrm{M}$ of imperatorin, and after simultaneous treatment with cisplatin $5 \mu \mathrm{M}$ and imperatorin $50 \mu \mathrm{M}$.

\section{Caspase 3 and LC3}

The effect of imperatorin on the expression of proapoptotic protein caspase 3 was time- and concentration-dependent (Figure 5A). After $6 \mathrm{~h}$ of treatment, no impact of the drug on the protein expression was observed, but longer incubation time (24 h) strongly increased its level, with maximum effectiveness at 50 $\mu \mathrm{M}$ (about $300 \%$ ). Treatment with $200 \mu \mathrm{M}$ of imperatorin had no effect on the protein expression. Increased protein expression (about 150\%) was observed only after incubation with imperatorin $100 \mu \mathrm{M}$, but higher concentrations diminished the protein level.

Cisplatin, at all the concentrations studied, had no significant effect on caspase 3 expression and the protein level was comparable with the control value (Figure 5B).

The effects of both drugs on the level of caspase 3 expression were dependent on the concentration and the sequence of drug treatment. When HeLa cells were incubated with $100 \mu \mathrm{M}$ of imperatorin and $2 \mu \mathrm{M}$ of cisplatin administered at the same time, overexpression of caspase 3 was observed (Figure 5C). Coincubation of cells with $2 \mu \mathrm{M}$ of cisplatin and $150 \mu \mathrm{M}$ of imperatorin decreased the protein level. In the variant with cisplatin preincubation, the level of the protein was lower than the control one. In the case of co-incubation of HeLa cells with cisplatin $5 \mu \mathrm{M}$ and 

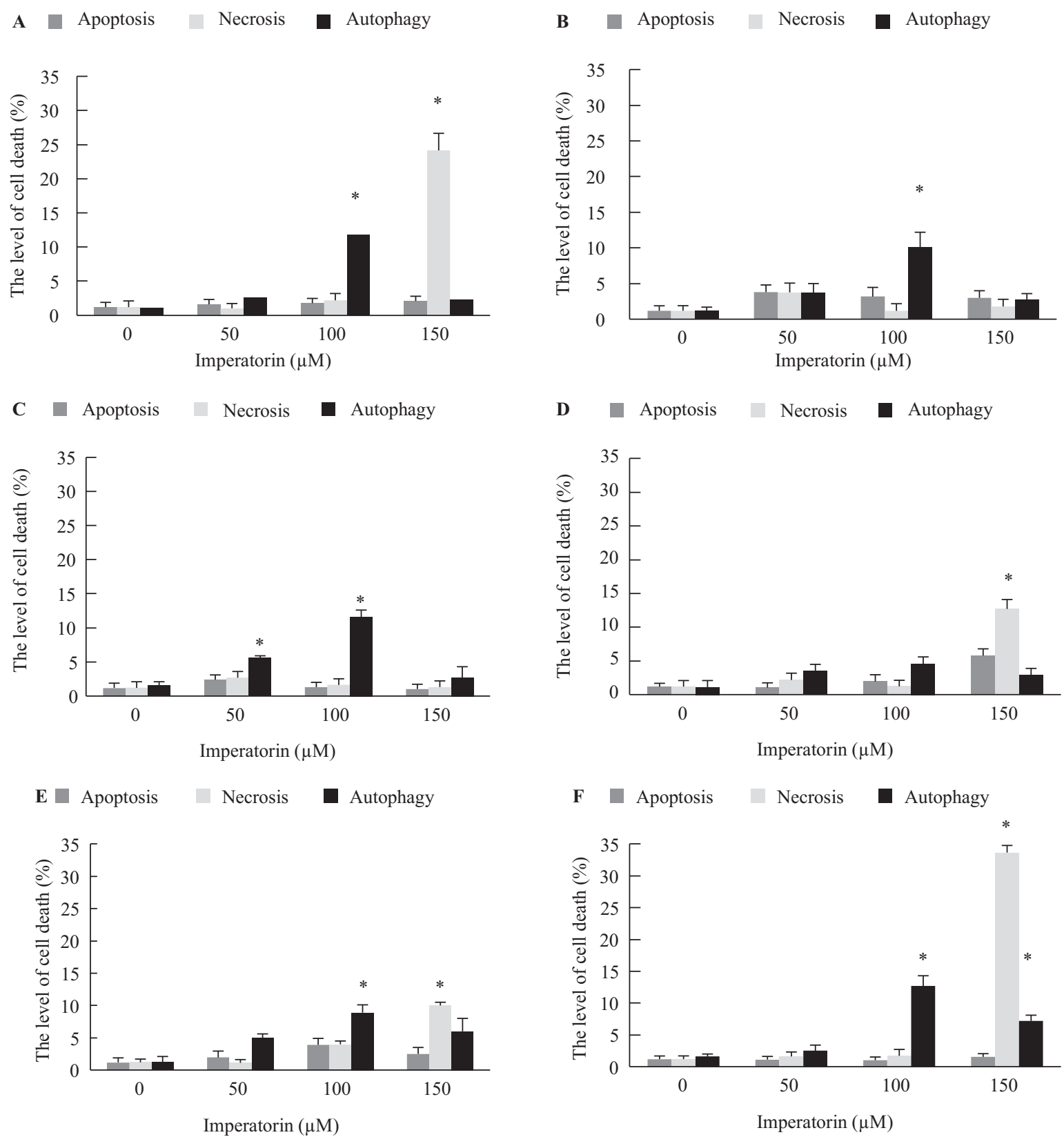

Figure 2. The levels of apoptosis, necrosis and autophagy induction after $24 \mathrm{~h}$ incubation of HeLa cells with different imperatorin concentrations and cisplatin $2 \mu \mathrm{M}(\mathbf{A}-\mathbf{C})$ or $5 \mu \mathrm{M}$ (D-F); A, D - incubation with both drugs at the same time, B, E - preincubation with imperatorin, followed by cisplatin treatment, $\mathrm{C}, \mathrm{F}$ - preincubation with cisplatin, followed by imperatorin treatment. ${ }^{*} \mathrm{p}<0.05$

imperatorin $50 \mu \mathrm{M}$, the level of caspase 3 was inhibited at all the variants of drug treatment (Figure 5D). Inhibition was also observed when the cells were preincubated with cisplatin followed by imperatorin treatment at the concentrations of $100 \mu \mathrm{M}$ and $150 \mu \mathrm{M}$. When the cells were preincubated with imperatorin at concentrations exceeding $50 \mu \mathrm{M}$, the level of caspase 3 reached the control one. Overexpression of the protein was observed after simultaneous treatment of HeLa cells with $100 \mu \mathrm{M}$ and $150 \mu \mathrm{M}$ of imperatorin and $5 \mu \mathrm{M}$ of cisplatin.
In the case of autophagy marker protein LC3, its cleavage into two forms, LC3I and LC3II, was observed after treatment with all the drug concentrations used in all experimental variants (Figure 6).

\section{Discussion}

There are conflicting reports concerning the effect of imperatorin on cancer cells. On the one hand, it has been indicated that imperatorin may be mutagenic, on the other hand, that it may inhibit mutagenesis 

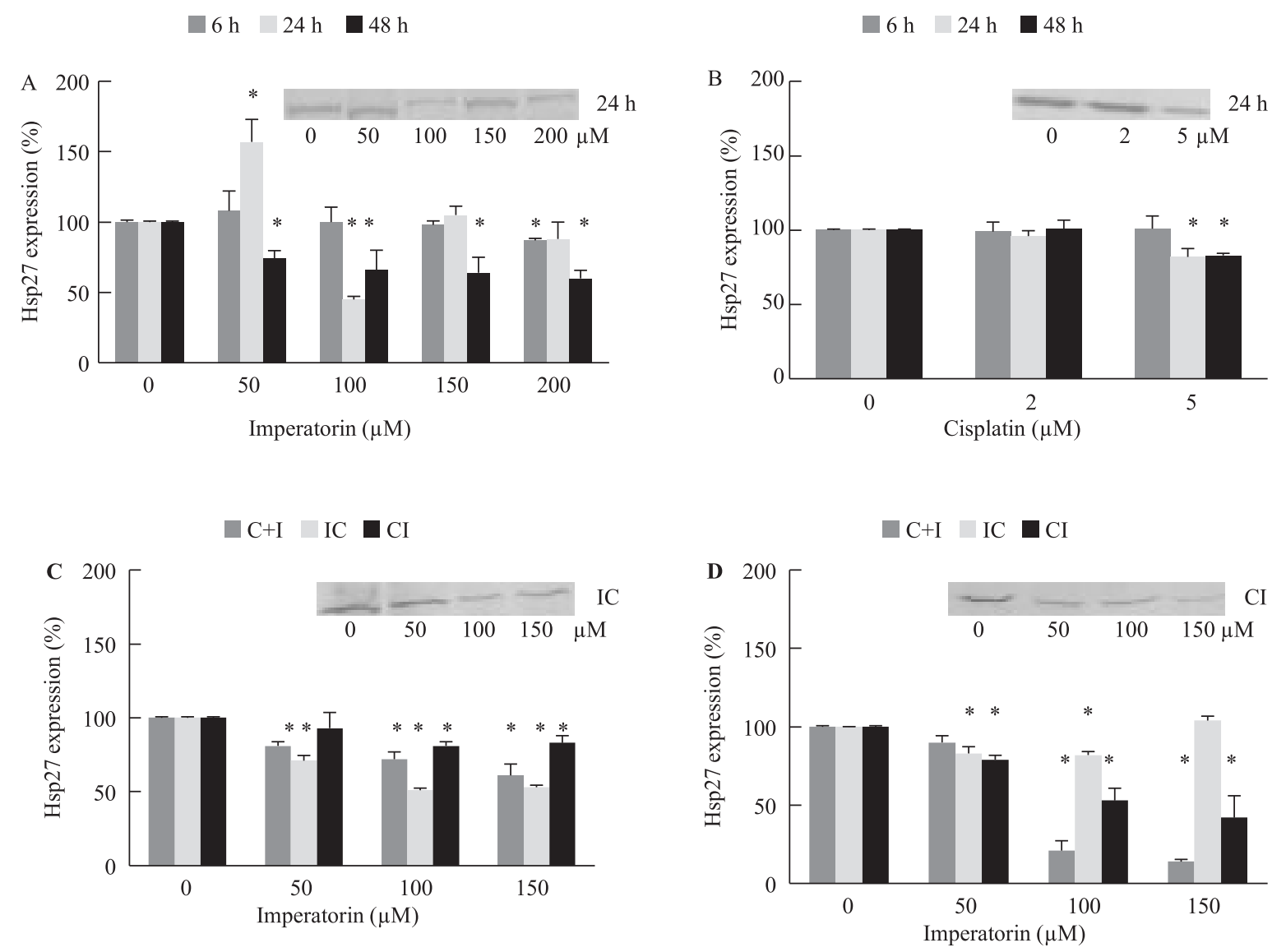

Figure 3. The effects of imperatorin (I) and cisplatin (C) on the level of Hsp27 expression. A - HeLa cells incubated with imperatorin $(0-200 \mu \mathrm{M}), \mathrm{B}-$ cells incubated with cisplatin $(0-5 \mu \mathrm{M}), \mathbf{C}-$ cells incubated with different imperatorin concentrations and cisplatin $2 \mu \mathrm{M}, \mathbf{D}$ - cells incubated with different imperatorin concentrations and cisplatin $5 \mu \mathrm{M}$; $\mathrm{C}+\mathrm{I}$ - incubation with both drugs at the same time, IC - preincubation with imperatorin, followed by cisplatin treatment, CI — preincubation with cisplatin, followed by imperatorin treatment. *p $<0.05$

and cancerogenesis [6, 7]. Induction of programmed cell death, like apoptosis and autophagy, is regarded as an important factor of cancerogenesis action. Thus, we decided to examine the effect of imperatorin on apoptosis, necrosis and autophagy in HeLa cells. Our results indicate that imperatorin was a potent autophagy inducer, especially at the concentration of $100 \mu \mathrm{M}$ after 24 hours of treatment and $150 \mu \mathrm{M}$ after $48 \mathrm{~h}$. A shorter incubation time was less effective. In contrast, cisplatin itself did not induce autophagy. At the molecular level, autophagy induction was correlated with specific expression of marker protein LC3. It is known that the cleavage of LC3 into two forms, LC3I and LC3II, is the hallmark of autophagy. LC3II participates in autophagosome formation and is associated with its structure. Accordingly, autophagy is associated with an increased ratio of LC3II to LC3I [28].

Several articles have appeared suggesting that induction of autophagy may block apoptosis [29]. In our experiments, imperatorin was a weak apoptosis in- ducer. Interestingly, it was correlated with strong caspase 3 expression, especially after $24 \mathrm{~h}$ and $48 \mathrm{~h}$ of treatment. It has been shown by other authors that imperatorin isolated from Cnidii monnieri fructus caused formation of apoptotic bodies, DNA fragmentation and enhanced degradation in HL-60 cells [30]. This was accompanied by activation of the cytochrome c-dependent pathway, mitochondrial membrane potential perturbation, release of cytochrome c, and in consequence, activation of caspase 3 and 9 [31]. Cisplatin induced apoptosis significantly only after $5 \mu \mathrm{M}$. It is known that cisplatin can induce apoptosis in caspase 3-dependent and -independent manners $[12,13]$. In our experiments, the activation of caspase 3 was not significant. The mechanism involved in resistance of tumor cells to cisplatin is not clearly understood. It is supposed that the induction of resistance may be associated with decreased cellular cisplatin accumulation, enhanced DNA repair and increased glutathione (GSH) or 
A

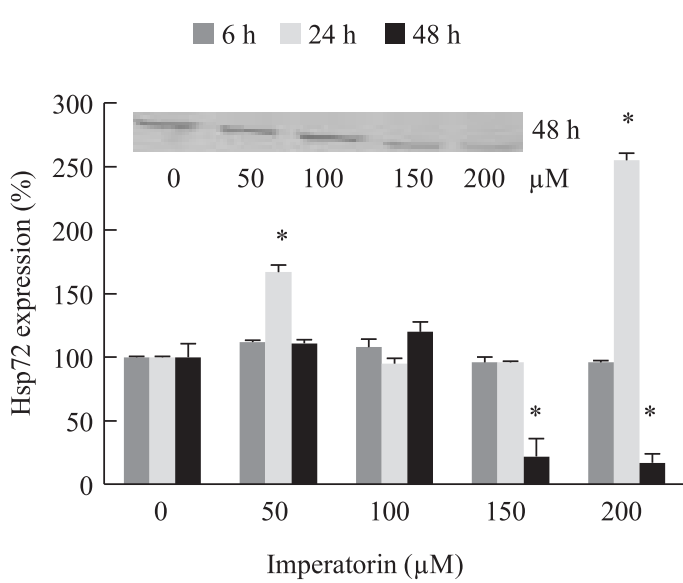

C
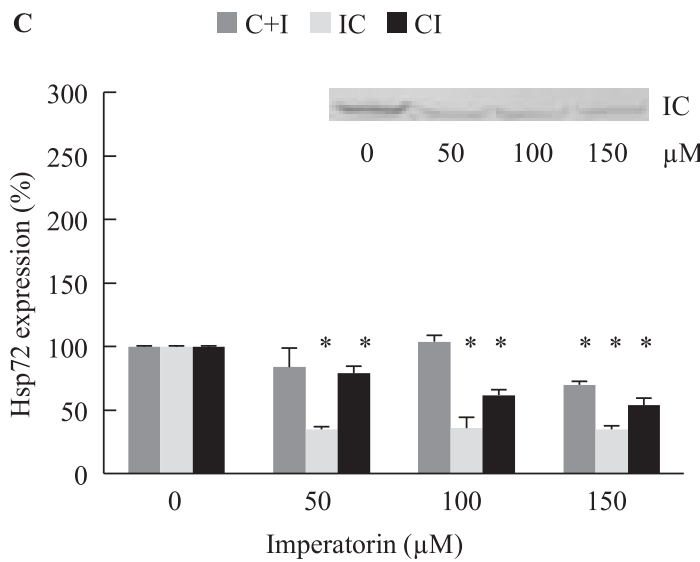

$\square \mathrm{b} \quad 24 \mathrm{~h} \quad \square 48 \mathrm{~h}$
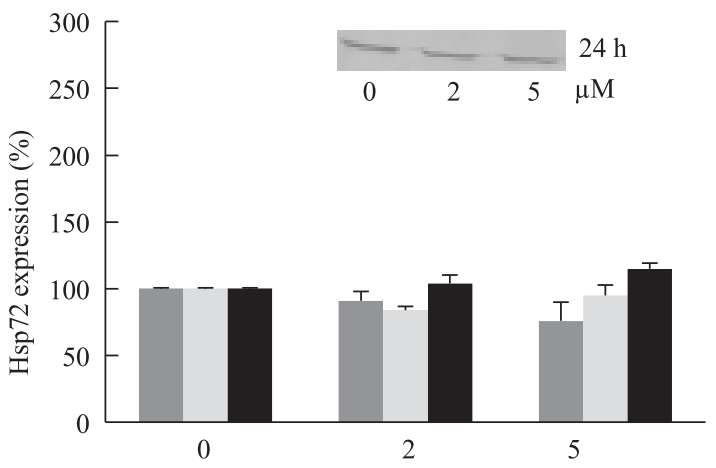

Cisplatin $(\mu \mathrm{M})$

D

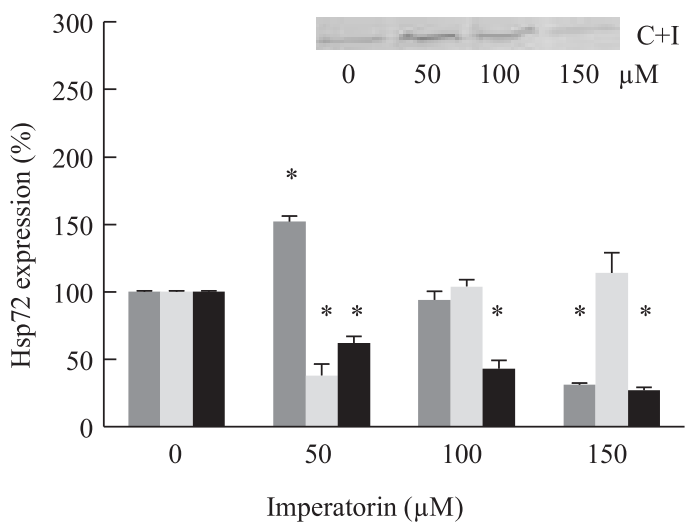

Figure 4. The effects of imperatorin (I) and cisplatin (C) on the level of Hsp72 expression. A - HeLa cells incubated with imperatorin $(0-200 \mu \mathrm{M}), \mathbf{B}-$ cells incubated with cisplatin $(0-5 \mu \mathrm{M}), \mathbf{C}-$ cells incubated with different imperatorin concentrations and cisplatin $2 \mu \mathrm{M}, \mathbf{D}$ - cells incubated with different imperatorin concentrations and cisplatin $5 \mu \mathrm{M}$; $\mathrm{C}+\mathrm{I}$ - incubation with both drugs at the same time, IC - preincubation with imperatorin, followed by cisplatin treatment, $\mathrm{CI}-$ preincubation with cisplatin, followed by imperatorin treatment. ${ }^{*} \mathrm{p}<0.05$

increased Hsps levels [32, 33]. In our experiments, cisplatin had no significant impact on Hsp72 expression and inhibited Hsp27 at the concentration of $5 \mu \mathrm{M}$ after $24 \mathrm{~h}$ and $48 \mathrm{~h}$ of treatment. At these concentrations, apoptosis as well as necrosis was observed, which may suggest the involvement of Hsp27 in cisplatin resistance of HeLa cells to death.

Many studies have demonstrated that natural plant extracts and natural compounds exhibit a synergistic anti-tumor effect with chemotherapeutics [34, 35]. Thus, we decided to examine the effect of imperatorin on the cisplatin-induced apoptosis of HeLa cells. We measured cell death in HeLa cells pretreated with imperatorin or cisplatin followed by cisplatin or imperatorin treatment and compared the effect to cell death induced by cisplatin and imperatorin used simultaneously. In our experiments, the combination of both drugs was most effective in autophagy induction, especially when imperatorin at the concentration of $100 \mu \mathrm{M}$ was present in the drug mixture. Sim- ilar results were observed after imperatorin itself. Surprisingly, the effectiveness of autophagy induction was smaller in the case of the combination than in the case of imperatorin alone. This may suggest that cisplatin diminishes the pro-autophagal properties of imperatorin. Autophagy induction was correlated with the increased level of cleaved form LC3II. Inhibition of Hsp72 and Hsp27 was also observed.

Neither drug at all the combinations had a significant effect on apoptosis induction. Only after simultaneous treatment of imperatorin over $100 \mu \mathrm{M}$ with cisplatin $5 \mu \mathrm{M}$ was an increased level of apoptotic cells observed. It was correlated with an increased level of caspase 3. Unfortunately, this was also accompanied by strong necrosis induction, suggesting a toxic effect of both drugs on the cell line. Our earlier results strongly suggested that the significant decrease in Hsp72 expression after pretreatment with a natural flavonoid, quercetin, was correlated with the highest sensitivity of HeLa cells to cispl- 

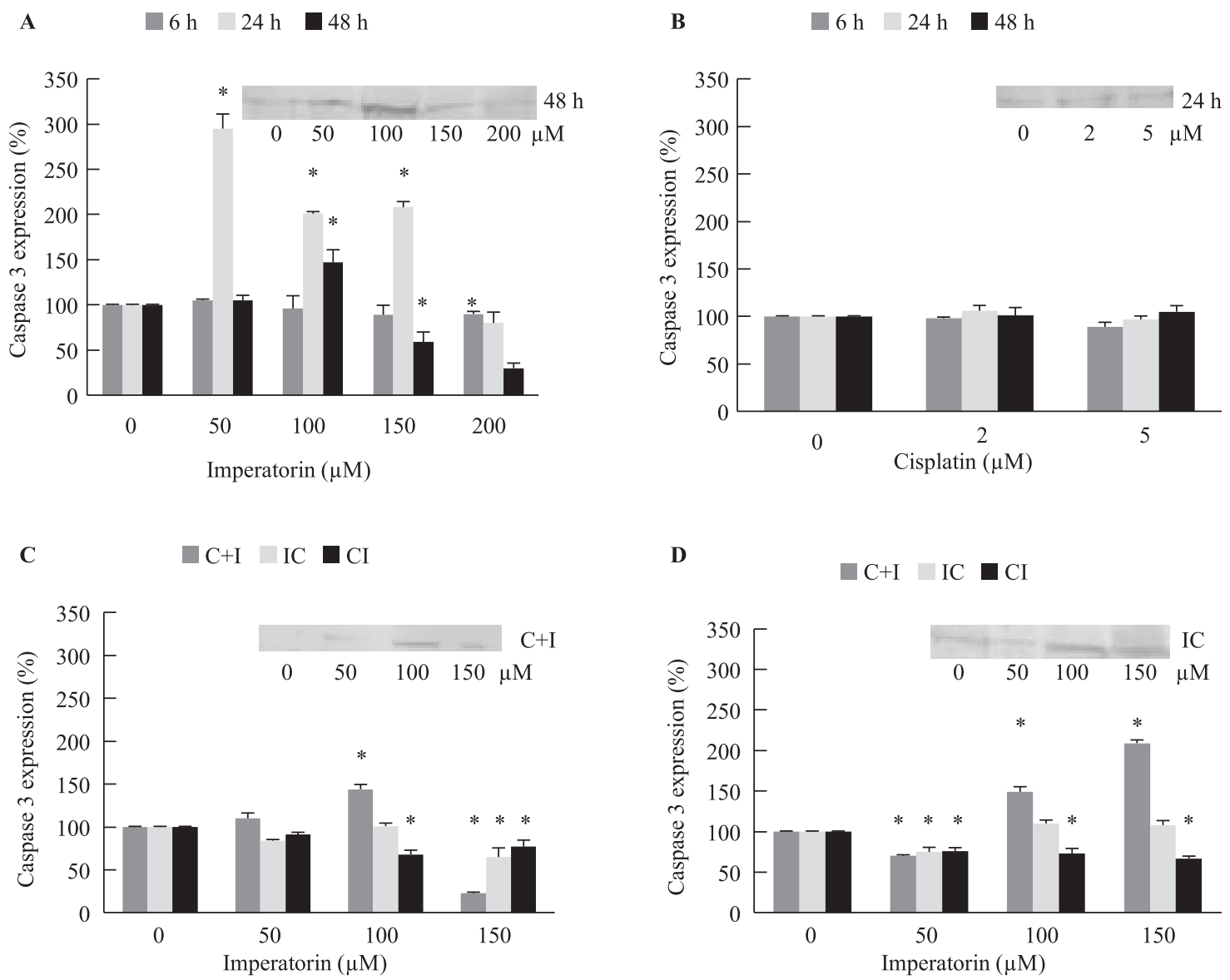

Figure 5. The effects of imperatorin (I) and cisplatin (C) on the level of caspase 3 expression. A - HeLa cells incubated with imperatorin $(0-200 \mu \mathrm{M}), \mathbf{B}-$ cells incubated with cisplatin $(0-5 \mu \mathrm{M}), \mathbf{C}-$ cells incubated with different imperatorin concentrations and cisplatin $2 \mu \mathrm{M}, \mathbf{D}$ - cells incubated with different imperatorin concentrations and cisplatin $5 \mu \mathrm{M}$; $\mathrm{C}+\mathrm{I}$ - incubation with both drugs at the same time, IC - preincubation with imperatorin, followed by cisplatin treatment, CI - preincubation with cisplatin, followed by imperatorin treatment. *p $<0.05$

atin-induced apoptosis [36]. In the present study, the inhibition of Hsp72 as well as Hsp27 by imperatorin was correlated with increased sensitivity to autophagy rather than apoptosis.

In summary, our results indicated that imperatorin alone, or in combination with cisplatin, was very effective in inducing autophagy in HeLa cells. The pro-autophagic activity of imperatorin was mediated by LC3 cleavage and the inhibition of heat shock proteins expression, especially Hsp27.

\section{References}

1. Ivie GW. Linear furanocoumarins (psoralens) from the seed of texas Ammi majus L. (Bishop's Weed). J Agric Food Chem. 1987;26:1394-1420.

2. Kawaii S, Tomono Y, Ogawa K et al. Antiproliferative effect of isopentenylated coumarins on several cancer cell lines. Anticancer Res. 2001;21:1905-1911.

3. Mori H, Niwa K, Zheng Q, Yamada Y, Sakata K, Yoshimi N. Cell proliferation in cancer prevention; effects of preventive agents on estrogen-related endometrial carcinogenesis model and on an in vitro model in human colorectal cells. Mutat Res. 2001;480-481:201-207.
4. Sancho R, Márquez N, Gómez-Gonzalo M et al. Imperatorin inhibits HIV-1 replication through an Sp1-dependent pathway. J Biol Chem. 2004;279:37349-37359.

5. Chou SY, Hsu CS, Wang KT, Wang MC, Wang CC. Antitumor effects of Osthol from Cnidium monnieri: an in vitro and in vivo study. Phytother Res. 2007;21:226-230.

6. Uwaifo AO. The mutagenicities of seven coumarin derivatives and a furan derivative (nimbolide) isolated from three medicinal plants. J Toxicol Environ Health. 1984;13:521-530.

7. Uwaifo AO, Billings PC, Heidelberger C. Mutation of Chinese Hamster V79 cells and transformation and mutation of mouse fibroblast $\mathrm{C} 3 \mathrm{H} / 10 \mathrm{Tl} / 2$ clone 8 cells by aflatoxin $\mathrm{B} 1$ and four other furocoumarins isolated from two Nigerian medicinal plants. Cancer Res. 1983;43:1048-1054.

8. Blankenberg FG. Recent advances in the imaging of programmed cell death. Curr Pharm Des. 2004;10:1457-1467.

9. Jakubowicz-Gil J, Paduch R, Gawron A, Kandefer-Szerszeń M. The effect of heat shock, cisplatin, etoposide and quercetin on Hsp27 expression in human normal and tumour cells. Folia Histochem Cytobiol. 2002;40:31-35.

10. Čipák L, Novotný L, Čipáková I, Rauko P. Differential modulation of cisplatin and doxorubicin efficacies in leukemia cells by flavonoids. Nutrition Res. 2003;23:1045-1057.

11. Sarto C, Binz P-A, Mocarelli P. Heat shock proteins in human cancer. Electrophoresis. 2000;21:1218-1226. 
A

LC3II $\square$ LC3I

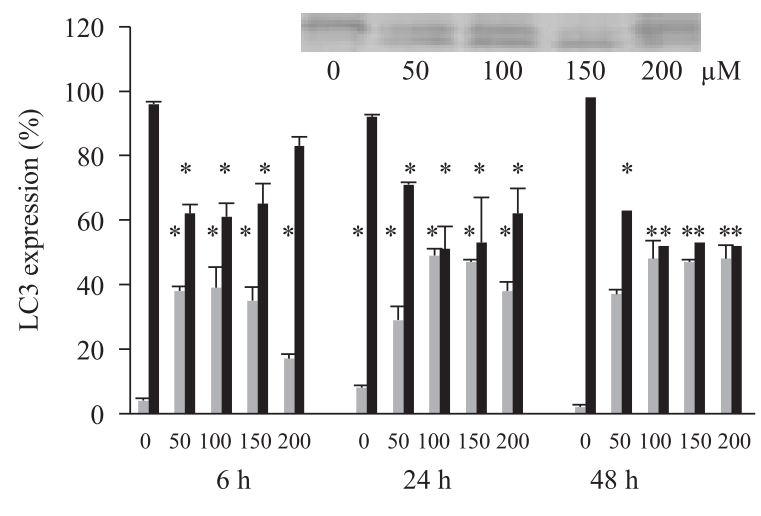

Imperatorin $(\mu \mathrm{M})$

C
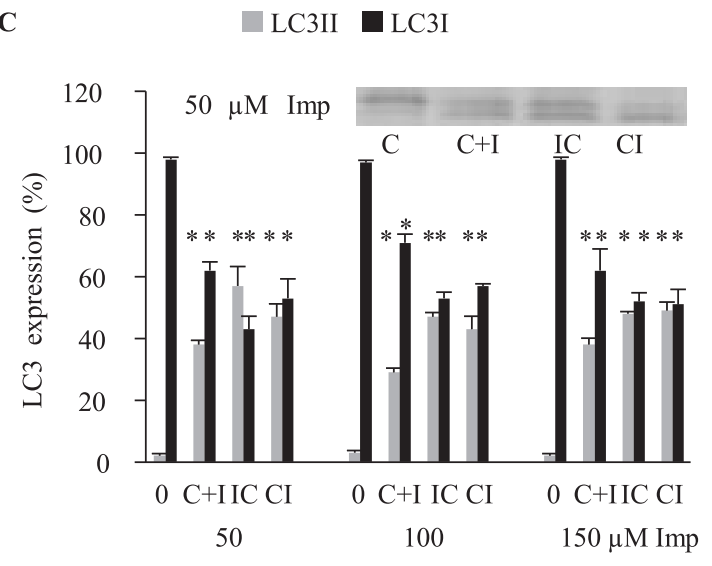

Imperatorin and cisplatin $(2 \mu \mathrm{M})$
B $\square$ LC3II $\square$ LC3I

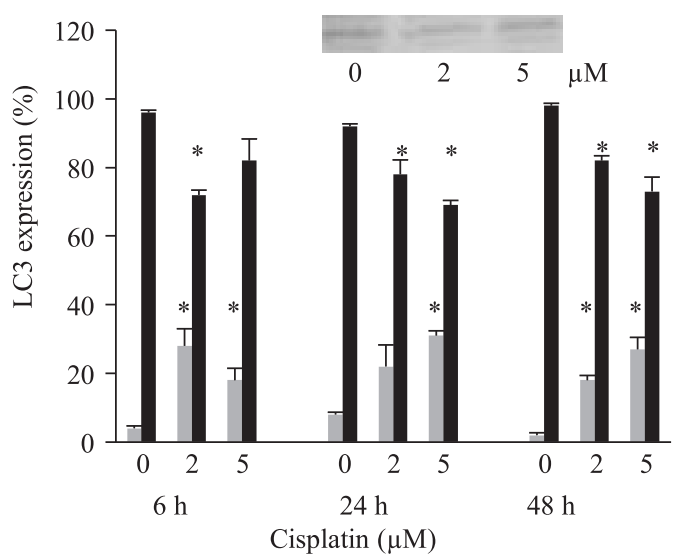

D $\square$ LC3II $\square$ LC3I

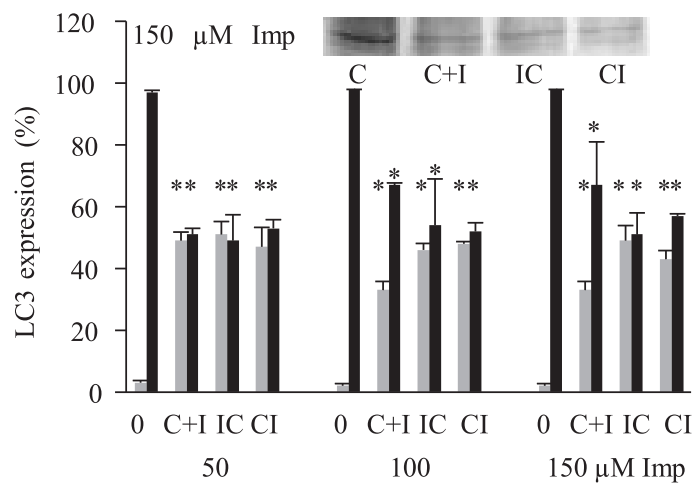

Imperatorin and cisplatin $(5 \mu \mathrm{M})$

Figure 6. The effects of imperatorin (I) and cisplatin (C) on the level of LC3 expression. A - HeLa cells incubated with imperatorin $(0-200 \mu \mathrm{M}), \mathbf{B}$ - cells incubated with cisplatin $(0-5 \mu \mathrm{M}), \mathbf{C}$ - cells incubated with different imperatorin concentrations and cisplatin $2 \mu \mathrm{M}, \mathbf{D}$ - cells incubated with different imperatorin concentrations and cisplatin $5 \mu \mathrm{M}$; $\mathrm{C}+\mathrm{I}$ - incubation with both drugs at the same time, IC - preincubation with imperatorin, followed by cisplatin treatment, $\mathrm{CI}$ - preincubation with cisplatin, followed by imperatorin treatment. * $\mathrm{p}<0.05$

12. Clark JI. Therapeutic applications of heat shock proteins and molecular chaperones. Expert Opinion on Therapeutic Patents. 2001;11:1153-1160.

13. Li W, Shen F, Weber G. Ribavidin and quercetin synergistically downregulate signal transduction and are cytotoxic in human ovarian carcinoma cells. Oncol Res. 1999;11:243-247.

14. Hettinga JVE, Lemstra W, Meijer C et al. Heat shock protein expression in cisplatin sensitive and resistant human tumour cells. Int J Cancer. 1996;67:800-807.

15. Birt DF, Hendrich S, Wang W. Dietary agents in cancer prevention: flavonoids and isoflavonoids. Pharmacol Therap. 2001;90:157-177.

16. Ferrandina G, Almadori G, Maggiano N et al. Growthinhibitory effect of tamoxifen and quercetin and presence of type II estrogen binding sites in human laryngeal cancer cell lines and primary laryngeal tumors. Int J Cancer. 1998;7: 747-754.

17. Cook NC, Samman S. Flavonoids-chemistry, metabolism, cardioprotective effects and dietary sources. Nutr Biochem. 1996;7:66-76.
18. Křepela E. Cysteine proteinases in tumour cell growth and apoptosis. Neoplasma. 2001;48:332-349.

19. Melendez-Zajgla J, Garcia C, Maldonado V. Subcellular redistribution of hsp 72 protein during cisplatin-induced apoptosis in Hela cells. Biochem Mol Biol Int. 1996;40: 153-261.

20. Schwarz E, Hauke L, Rainer R. The effect of molecular chaperones on in vivo and in vitro folding processes. Biol Chem. 1996;377:411-416.

21. Morel I, Lescoat G, Cogrel P et al. Antioxidant and ironchelating activities of the flavonoids catechin, quercetin and diosmetin on iron-loaded rat hepatocyte cultures. Biochem Pharmacol. 45:13-19.

22. Lefranc F, Facchini V, Kiss R. Proautophagic drugs: A novel means to combat apoptosis-resistant cancers, with a special emphasis on gliomas. Oncologist. 2007;12:1395-1403.

23. Bradford MM. A rapid and sensitive method for quantitation of microgram quantities of protein utilizing the principle of protein-dye binding. Anal Biochem. 1976;72: 248-254. 
24. Laemmli UK. Cleavage of structural proteins during the assembly of the head of bacteriophage T4. Nature. 1970;227:680-685.

25. Jankowska A, Skonieczna D, Rommerts FFC, Warchoł JB. Investigations on apoptosis in Leydig cells cultured in vitro. Folia Histochem Cytobiol. 1997;33:99-110.

26. Takeuchi H, Kondo Y, Fujiwara K, Kanzawa T, Aoki H, Mills GB, Kondo S. Synergistic augmentation of rapamycininduced autophagy in malignant glioma cells by phosphatidylinositol 3-kinase/protein kinase B inhibitors. Cancer Res. 2005; 65:3336-3346.

27. Chou TC, Talalay P. Analysis of combined drug effects: a new look at a very old problem. Trends Pharmacol Sc. 1983;4:450-454.

28. Kabeya Y, Mizushima N, Ueno T et al. LC3 a mammalian homologue of yeast Apg8p is localized in autophagosome membranes after processing. EMBO J. 2000;19:5720-5728.

29. Kaushal GP, Kaushal V, Herzog C, Yang C. Autophagy delays apoptosis in renal tubular epithelial cells in cisplatin cytotoxicity. Autophagy. 2001;4:710-712.

30. Yang LL, Wang MC, Chen LG, Wang CC. Cytotoxic activity of coumarins from the fruits of Cnidium monnieri on leukemia cell lines. Planta Med. 2003;69:1091-1095.

31. Pae HO, Oh H, Yun YG et al. Imperatorin, a furanocoumarin from Angelica dahurica (Umbelliferae), induces cytochrome c-dependent apoptosis in human promyelocytic leukaemia, HL-60 cells. Pharmacol Toxicol. 2002;91:40-48.

32. Perez RP. Cellular and molecular determinants of cisplatin resistance. Eur J Cancer. 1998;34:1535-1542.
33. Zhang K, Chew M, Yang EB, Wong LP, Mack P. Modulation of cisplatin cytotoxicity and cisplatin-induced DNA cross-links in HepG2 cells by regulation of glutathione-related mechanisms. Mol Pharmacol. 2001;59:837-843.

34. Ramos S. Effects of dietary flavonoids on apoptotic pathways related to cancer chemoprevention. J Nutr Biochem. 2007; 18:427-442.

35. Russo GL. Ins and outs of dietary phytochemicals in cancer chemoprevention. Biochem Pharmacol. 2007;22:317-320.

36. Jakubowicz-Gil J, Paduch R, Piersiak T, Głowniak K, Gawron A, Kandefer-Szerszeń M. The effect of quercetin on pro-apoptotic activity of cisplatin in HeLa cells. Biochem Pharmacol. 2005 69:1343-1350.

37. Luo KW, Sun JG, Chan JY et al. Anticancer effects of imperatorin isolated from Angelica dahurica: induction of apoptosis in HepG2 cell through both death-receptor- and mitochondria-mediated pathways. Chemother. 2011;57: 449-459.

38. Zhang Y, Shen X. Heat shock protein 27 protects L929 cells from cisplatin-induced apoptosis by enhancing akt activation and abating suppression of thioredoxin reductase activity. Clin Cancer Res. 2007;13:2855-2864.

39. Senol FS, Skalicka-Woźniak K, Khan MTH, Orhan IE, Sener B, Głowniak K. An in vitro and in silico approach to cholinesterase inhibitory and antioxidant effects of the methanol extract, furanocoumarin fraction, and major coumarins of Angelica officinalis L. fruits. Phytochem Lett. 2011;4: 462-467. 